Check for updates

Cite this: RSC Adv., 2017, 7, 50347

Received 4th August 2017

Accepted 11th October 2017

DOI: $10.1039 / \mathrm{c} 7 \mathrm{ra0} 8610 \mathrm{e}$

rsc.li/rsc-advances

\section{Role of lanthanum vacancy on the structural, magnetic and magnetocaloric properties in the lacunar perovskite manganites $\mathrm{La}_{0.8-x} \square_{x} \mathrm{Na}_{0.2} \mathrm{MnO}_{3}(0 \leq x \leq 0.15)$}

\author{
S. Choura-Maatar, ${ }^{a}$ R. M'nassri, (D)*b W. Cheikhrouhou-Koubaa, ${ }^{a}$ M. Koubaa, ${ }^{a}$ \\ A. Cheikhrouhou ${ }^{a}$ and E. K. Hlil ${ }^{\mathrm{C}}$
}

Lacunar $\mathrm{La}_{0.8-x} \square_{x} \mathrm{Na}_{0.2} \mathrm{MnO}_{3}(0 \leq x \leq 0.15)$ ceramics where $\square$ is a lanthanum deficiency were synthesized via a sol-gel method. Magnetic phase transitions and magnetocaloric effects of the ceramics have been systematically studied. Structural studies using X-ray diffraction show that all compounds crystallize in the rhombohedral structure with an $R \overline{3} c$ space group. The lanthanum deficiency does not modify the crystal structure of the pristine compound $(x=0)$ but results in a slight change of the lattice parameters. The unit cell volume and $\mathrm{Mn}-\mathrm{O}-\mathrm{Mn}$ angle decrease with increasing deficiency content whereas the $\mathrm{Mn}-\mathrm{O}$ bond length increases. This situation weakens the double-exchange interaction and hence reduces the Curie temperature $\left(T_{C}\right)$. By analyzing the temperature and field dependence of magnetization, we find that the $\mathrm{La}_{0.8-x} \square_{x} \mathrm{Na}_{0.2} \mathrm{MnO}_{3}$ family exhibits a second order magnetic phase transition whose critical temperature is tunable near room temperature. A considerable magnetic entropy change is observed in $\mathrm{La}_{0.8-} \square_{x} \mathrm{Na}_{0.2} \mathrm{MnO}_{3}$ near room temperature. The maximum value of the relative cooling power (RCP) is found to be $\sim 268 \mathrm{~J} \mathrm{~kg}^{-1}$ in $L_{0.65} \square_{0.15} \mathrm{Na}_{0.2} \mathrm{MnO}_{3}$ at $5 \mathrm{~T}$. This value of RCP is about $\sim 65.3 \%$ of that obtained in gadolinium metal, known as one of the most important materials for magnetic refrigeration, at the same magnetic field change of $5 \mathrm{~T}$. With increasing vacancy our manganites exhibit a stable magnetocaloric effect in a wide temperature range. The results suggest that $\mathrm{La}_{0.8-x} \square_{x} \mathrm{Na}_{0.2} \mathrm{MnO}_{3}$ and its composite materials could be expected to have effective applications for magnetic refrigeration near room temperature.

\section{Introduction}

Reversible magnetic-field-driven thermal changes are known as magnetocaloric effects (MCE) and have been proposed for magnetic refrigeration (MR) technology. ${ }^{1}$ The latter is a technology used to warm and cool in response to the application and removal of an external magnetic field, and it receives comprehensive attention due to its several apparent advantages over traditional vapor compression based cooling technologies: high cooling efficiency, environmentally friendly technology and convenient for miniaturization. ${ }^{2-4}$ The MCE refers to an induced temperature change $\left(\Delta T_{\mathrm{ad}}\right)$ and/or entropy change $(\Delta S)$ caused by introducing a magnetic field change to a magnetic material. ${ }^{5,6}$ This effect originates from the coupling of

${ }^{a}$ LT2S Lab (LR16 CNRS 01), Digital Research center of Sfax, Sfax Technopark. Cité El Ons, B.P. 275, 3021 Sfax, Tunisia

${ }^{b}$ Unité de Recherche Matériaux Avancés et Nanotechnologies (URMAN), Institut Supérieur des Sciences Appliquées et de Technologie de Kasserine, Kairouan University, BP 471 Kasserine 1200,Tunisia.E-mail: rafik_mnassri@yahoo.fr

'Institut Néel, CNRS, Université Grenoble Alpes, BP 166, F-38042 Grenoble cedex 9, France a magnetic field with magnetic moments in a solid. Magnetic entropy change is known to achieve relatively high values at finite temperatures near ferromagnetic and antiferromagnetic phase transition. Theoretical predictions and experimental results for various classes of material like manganites confirm that the magnetic entropy change is larger for the first than for the second order phase transition. However, physical properties in manganites are strongly affected by the modification of the average cationic size, ${ }^{7}$ cationic disorder, ${ }^{8}$ doping level, ${ }^{9}$ grain boundary engineered ${ }^{\mathbf{1 0}}$ particle size ${ }^{\mathbf{1 1}}$ and oxygen stoichiometry. ${ }^{12}$ The induce distortion of the $\mathrm{MnO}_{6}$ octahedron thereby changes the distance and angle between the $\mathrm{Mn}-\mathrm{O}-\mathrm{Mn}$ ions. Moreover, a strong electron-phonon interaction arising from the Jahn-Teller splitting of the outer Mn d level ${ }^{13}$ and the oxygen deficiency plays a role in the electrical and magnetic properties of lanthanum manganites. Also, it is well known that any magnetic transitions, or even changes in magnetic properties with temperature or magnetic field, are accompanied by transformation or, at least, some spontaneous deformation of the crystal lattice. These distortions are evidenced by several techniques such as Raman spectroscopy. ${ }^{\mathbf{1 4}}$ The observation of 
structural changes in doped manganites in the presence of a magnetic stimulus can be explained by the orthorhombic distortions, which can be tuned by an applied magnetic field. Based on the interplay between the double exchange and JahnTeller electron-phonon coupling, this phenomenon is interpreted as spectroscopic evidence of the strong coupling between the magnetic field and the lattice leading to an additional tunable charge carrier localization in the double exchange model. In the context of MCE compounds, the changes in the microstructure of the material can produce local inhomogeneities around the $\mathrm{Mn}$ atoms, and a distribution of the $\mathrm{Mn}-\mathrm{Mn}$ interatomic distances affecting the exchange interactions. These alterations would change the value of the Curie temperature $\left(T_{\mathrm{C}}\right)$ in the sense that instead of a unique value for $T_{\mathrm{C}}$, a more reliable picture considers also a distribution function for this magnitude in the prepared sample. The latter distribution of $T_{\mathrm{C}}$ values can make a modification to the nature of the transition and induces a broadening of the magnetic entropy change plots. ${ }^{15}$ The technical parameter called the relative cooling power (RCP) also depends on the width of the transition temperature interval ${ }^{16}$ and determines the applicability of materials for solid-state cooling applications. In developing MCE materials with large magnetocaloric properties, many community efforts are currently devoted to MCE materials that can generate a large adiabatic temperature change $\left(\Delta T_{\mathrm{ad}}\right)$ and isothermal entropy change $(\Delta S)$; however, these MCE materials can require very high magnetic fields, which further limits practical purposes. There are a number of different magnetocaloric materials available for use in magnetic refrigeration such as pure Gd and manganites; these are systematically described in several reviews in the literature. ${ }^{\mathbf{1 , 5 , 1 7 , 1 8}}$ Recently, Bahl et al. ${ }^{19}$ have demonstrated the potential of manganites as working magnetocaloric substances for application in devices. For this purpose, lanthanum manganites and their derivatives have secured a prominent position in the MCE phenomenon as they possess high magnetic moments and are ferromagnetic in nature. ${ }^{5,20,21}$ This class of material has good wear resistance, high thermal and chemical stability, uncomplicated preparation, low cost and energy-efficiency, grain growth to a desired size via heat treatment and, more importantly, the ability to control the magnetic transition temperatures close to room temperature by substitutions which make the material useful for solid-state cooling applications. ${ }^{11,22}$ These oxides, inexpensive and abundant, are known only to a limited extent, and a search for new refrigerant materials and new synthesis routes leading to a stronger magnetocaloric effect is still desired. However, only a small number of investigations have been proposed to discuss the deficiency effect in MCE-manganite materials. The presence of a cationic vacancy on the A-site of the perovskite lattice cell is an alternative way to introduce a modification in the average ionic radius $\left\langle r_{\mathrm{A}}\right\rangle$ of the A site and also an additional change in the $\mathrm{Mn}^{4+}$ content. This change affects the lattice parameters and in particular the $\mathrm{Mn}-\mathrm{O}-\mathrm{Mn}$ networks and can thus enhance the super-exchange interactions and consequently, $T_{\mathrm{C}}$ may be diminished. ${ }^{23,24}$ In continuation of previous work from our laboratory, we have investigated the effect of a cationic vacancy in the A-site on the physical properties of manganites. ${ }^{25-27}$ This investigation is also of interest to the magnetocaloric behaviors in lacunar systems. In the present study, we synthesized novel lacunar manganite $\mathrm{La}_{0.8-x} \square_{x} \mathrm{Na}_{0.2} \mathrm{MnO}_{3}$ with different A-site vacancy amounts by the Pechini-type sol-gel process and studied the structural, magnetic and magnetocaloric effects due to the presence of $\mathrm{La}^{3+}$ concentration deficiencies.

\section{Materials production}

Polycrystalline $\mathrm{La}_{0.8-x} \square_{x} \mathrm{Na}_{0.2} \mathrm{MnO}_{3}$ samples where $\square$ is a lanthanum vacancy were prepared by a modified Pechini-type sol-gel method. High purity (99.9\%) precursors $\mathrm{La}_{2} \mathrm{O}_{3}, \mathrm{Na}_{2} \mathrm{CO}_{3}$ and $\mathrm{MnO}_{2}$ were taken as starting materials in an appropriate stoichiometric ratio. The precursor solution was prepared by dissolving the starting materials in a concentrated nitric acid solution in order to convert them into nitrates. During this procedure, the solution was continuously heated and stirred using a magnetic stirrer at $60{ }^{\circ} \mathrm{C}$ in order to accelerate the dissolution. After that, one adds citric acid (CA) and ethylene glycol (EG) as chelating agents until a completely homogeneous and transparent solution is obtained. These chelators serve to adjust the viscosity of the complex solution and control the moving velocity of the metal cations, resulting in the gelation of the reaction mixture. The product mixture was heated at $80{ }^{\circ} \mathrm{C}$ under constant stirring and the polyesterification reaction between citric acid and ethylene glycol takes place. After slowly drying the solution at $130{ }^{\circ} \mathrm{C}$, a residue of high viscosity is formed and a transparent gel is developed during the heating process. In a later step, the obtained gel is heated to $300{ }^{\circ} \mathrm{C}$ with a heating rate of $10^{\circ} \mathrm{C}$ per minute with the purpose of having the propagation of a combustion which transforms the freezing gel into fine powder. The resulting powders were then calcined at $450{ }^{\circ} \mathrm{C}$ in a furnace for $6 \mathrm{~h}$, in order to expel the organics from the material. The final black powders were then pressed into a pellet (of about $1 \mathrm{~mm}$ thickness and $13 \mathrm{~mm}$ diameter) followed by sintering at 900 and $950{ }^{\circ} \mathrm{C}$ for 24 hours in air with intermediate regrinding and repelling.

\section{Physical measurements}

To understand the structural properties of the samples under study, XRD measurements were performed at room temperature. The lattice structure and cell parameters of the $\mathrm{La}_{0.8-x} \square_{x} \mathrm{Na}_{0.2} \mathrm{MnO}_{3}$ system were characterized by diffraction (XRD) data, recorded on a PANalytical X'PERT Pro MPD diffractometer, using $\theta / 2 \theta$ Bragg-Brentano geometry with diffracted beam monochromatized CuK $\alpha$ radiation $(\lambda=1.5406 \AA)$. The diffraction patterns were collected by steps of $0.017^{\circ}$ over the angle range $10-100^{\circ} / 5-90^{\circ}$ for $x=0$ and $x=0.05 / x=0.1$ and $x=0.15$. Structural analysis was carried out using the standard Rietveld procedure ${ }^{28}$ built-in FULLPROF software $^{29}$ which minimizes the difference between the observed and simulated powder diffraction patterns. Magnetization measurements versus temperature and versus the magnetic applied field up to 5 T were carried out using BS1 and BS2 extraction type magnetometers. The used magnetometers are employed 
respectively for magnetic measurements at high and low temperatures equipped with a super conducting coil developed at the NEEL Institute. These magnetometers use an extraction technique and can produce a field of $7 \mathrm{~T}$ for BS1 and $11 \mathrm{~T}$ for BS2. The sample temperature is controlled by circulating helium gas. These two instruments are automated by a computer system that allows the registration of digital data for each successive measurement. $M(T)$ data were obtained under a magnetic applied field of $0.05 \mathrm{~T}$ in the field cooled mode (FC). Isothermal $M\left(\mu_{0} H\right)$ data were measured up to $5 \mathrm{~T}$. The MCE results were deduced from the magnetization measurements versus magnetic applied field up to $5 \mathrm{~T}$ at several temperatures.

\section{Results and discussion}

\subsection{Structural study}

The X-ray powder diffraction patterns registered at $300 \mathrm{~K}$ for $\mathrm{La}_{0.8-x} \square_{x} \mathrm{Na}_{0.2} \mathrm{MnO}_{3}$ compounds are depicted in Fig. 1 and indicate that all the samples have the same perovskite structure. The diffraction peaks can be indexed in the rhombohedral setting of the $R \overline{3} c$ space group $(Z=6)$ in which $\mathrm{La} / \mathrm{Na}$ atoms are located at the $6 \mathrm{a}(0,0,1 / 4)$ position, Mn atoms at the $6 \mathrm{~b}(0,0,0)$ position, and $\mathrm{O}$ atoms at the $18 \mathrm{e}(x, 0,1 / 4)$ position. Fig. 1 shows typical XRD patterns for $\mathrm{La}_{0.8-x} \square_{x} \mathrm{Na}_{0.2} \mathrm{MnO}_{3}$ samples including the observed and calculated profiles as well as the difference profile. The data were refined by the Rietveld technique using FULLPROF software. ${ }^{30}$ The refinement produced satisfactory agreement factors and lattice parameters which are listed in Table 1. In fact, we noticed the existence of diffraction peaks with very small intensities in the XRD patterns for the lacunar samples. This is due to the presence of small amounts of $\mathrm{Mn}_{3} \mathrm{O}_{4}$, which is frequently encountered after the final step in the synthesis of mixed-valence manganites. Given the small concentration of $\mathrm{Mn}_{3} \mathrm{O}_{4}$, we assume that the secondary phase does not have any significant effect on the perovskite stoichiometry according to ref. 31 .

Lanthanum vacancies did not affect the space group of the parent compound $\mathrm{La}_{0.8} \mathrm{Na}_{0.2} \mathrm{MnO}_{3}$. With increasing Ladeficiency amount, the room temperature unit cell volume is systematically decreased (see Fig. 2). Basically, the introduction of the vacancy $(x)$ in the A site implies a partial conversion of $\mathrm{Mn}^{3+}$ to $\mathrm{Mn}^{4+}$ ions according to the formula $\mathrm{La}_{0.8-x}{ }^{3+} \square_{x} \mathrm{Na}_{0.4}{ }^{+} \mathrm{Mn}_{0.8-3 x}{ }^{3+} \mathrm{Mn}_{0.2+3 x}{ }^{4+} \mathrm{O}_{3}{ }^{2-}$ and surely a change in the average ionic radius $\langle A\rangle$ of this site. In our case, the increase of the lanthanum-deficiency content $(x)$ leads to an increase of the Mn tetravalent ion number with a smaller radius $\left(r_{\mathrm{Mn}^{4+}}=0.53 \AA\right.$ and $r_{\mathrm{Mn}^{3+}}=0.65 \AA$ (ref. 32)). This increase in $\mathrm{Mn}^{4+}$ content induced a decrease in the average size of the B-site cation. Also, and for electrostatic considerations, a vacancy has an average radius $\left\langle r_{\mathrm{v}}\right\rangle \neq 0$ and leads to a change in the average ionic radius. These two effects explain the decrease of the unit cell volume. A similar result has been observed in other lacunar manganite systems such as $\operatorname{Pr}_{0.7-x} \square_{x} \mathrm{Sr}_{0.3} \mathrm{MnO}_{3}$ (ref. 33) and $\mathrm{La}_{0.65-x} \square_{x} \mathrm{Ca}_{0.35} \mathrm{MnO}_{3}{ }^{34}$

It is known that the magnetic state of a manganite system is very sensitive to changes in the $\mathrm{Mn}-\mathrm{O}-\mathrm{Mn}$ bond lengths and angles. For this reason, the average $\mathrm{Mn}-\mathrm{O}$ bond length and
Mn-O-Mn bond angle are extracted from the Rietveld refinement at room temperature and are depicted in Fig. 2. It is clear that the decrease of unit cell volume with the increase of La-deficiency is accompanied by an increase of $\langle\mathrm{Mn}-\mathrm{O}\rangle$ length and a decrease of $\langle\mathrm{Mn}-\mathrm{O}-\mathrm{Mn}\rangle$ bond angle of $\mathrm{MnO}_{6}$ (corresponding to the small tilts of oxygen octahedra which accommodate the elongation of the bond). Both variations compensate one another to diminish the internal strain induced by the La-deficiency amount, thereby enlarging the octahedral distortion. Since the exchange interaction between Mn-Mn depends on both the bond angle and the bond distance, the decrease in bond angle and the increase in bond length decrease the $\mathrm{Mn}-\mathrm{Mn}$ exchange interaction which leads to a lower magnetic ordering temperature $T_{\mathrm{C}}$ and produces a change in the thermomagnetic properties as evident in the magnetic data which follows.

\subsection{Magnetic properties}

The normalized magnetization-temperature curves, measured at a constant magnetic field equal to $0.05 \mathrm{~T}$, after field cooling (FC) mode for all samples, are depicted in Fig. 3-a. The latter show clearly a transition from a paramagnetic (PM) to a ferromagnetic (FM) state with decreasing temperature. This type of transition has already been observed in other lacunar manganites such as $\mathrm{La}_{0.6} \mathrm{Sr}_{0.2} \mathrm{Ba}_{0.2-x} \square_{x} \mathrm{MnO}_{3}$ (ref. 27) and $\mathrm{Pr}_{0.7-x} \square_{x} \mathrm{Sr}_{0.3} \mathrm{MnO}_{3}{ }^{33}$ A reasonable estimation of the Curie temperature $T_{\mathrm{C}}$ can be obtained by determining the temperature of the minimum differential quotient of magnetization $(\mathrm{d} M(T) / \mathrm{d} T)$. Fig. 3-b shows that the magnitudes and shapes of the $\mathrm{d} M / \mathrm{d} T$ curves are varied depending on the vacancy level, which renders some indications regarding the sample homogeneity. These curves reveal a strong variation of magnetization around the Curie temperature $T_{\mathrm{C}}$, defined as the temperature at which the $(\mathrm{d} M / \mathrm{d} T-T)$ curve reaches a minimum. This indicates that there is a possible large magnetic entropy change around $T_{\mathrm{C}}$. A slight shift in $T_{\mathrm{C}}$ towards lower temperatures is also observed with increasing the lanthanum-deficiency content $(x)$. The inset of Fig. 3-b shows the Curie temperatures $T_{\mathrm{C}}$ of $\mathrm{La}_{0.8-x} \square_{x} \mathrm{Na}_{0.2} \mathrm{MnO}_{3}$ for different $x$ amounts. The decrease in $T_{\mathrm{C}}$ is obviously related to an increase in the rate of $\mathrm{Mn}^{4+}$, since the antiferromagnetic super-exchange interaction $\mathrm{Mn}^{4+}-\mathrm{O}-$ $\mathrm{Mn}^{4+}$ is strengthened with the ferro-double exchange interaction $\mathrm{Mn}^{3+}-\mathrm{O}-\mathrm{Mn}^{4+}$. However, Table 1 contains an evaluation of the charge carrier bandwidth $W$ through the empirical formula $W \propto \cos (\theta / 2) / \mathrm{Mn}-\mathrm{O}^{3.5}$ (where $\theta=180^{\circ}$ is the tilt angle in the Mn-O-Mn plane). It is found that the bandwidth $W$ decreases with increasing lanthanum-deficiency. This decrease reduces the overlap between the $\mathrm{O}-2 \mathrm{p}$ and the Mn-3d orbitals, which in turn decreases the exchange coupling of $\mathrm{Mn}^{3+}-\mathrm{Mn}^{4+}$ as well as the magnetic ordering temperature $T_{\mathrm{C}} \cdot{ }^{13}$

The inverse of the susceptibility $\chi^{-1} \sim 1 / M$ (calculated from the data of Fig. 3-a) is shown in Fig. 3-c, as a function of temperature in the PM region $\left(T>T_{\mathrm{C}}\right)$ for $x=0.05$ and $x=0.15$. It can be fitted by a Curie Weiss $\operatorname{law}^{34} \chi=\mathrm{C} /\left(T-\Theta_{\mathrm{p}}\right)$ where $C$ is the Curie constant and $\Theta_{\mathrm{p}}$ is the paramagnetic Weiss temperature. From the linearity of the $\chi^{-1}$ curve for all of our materials, 

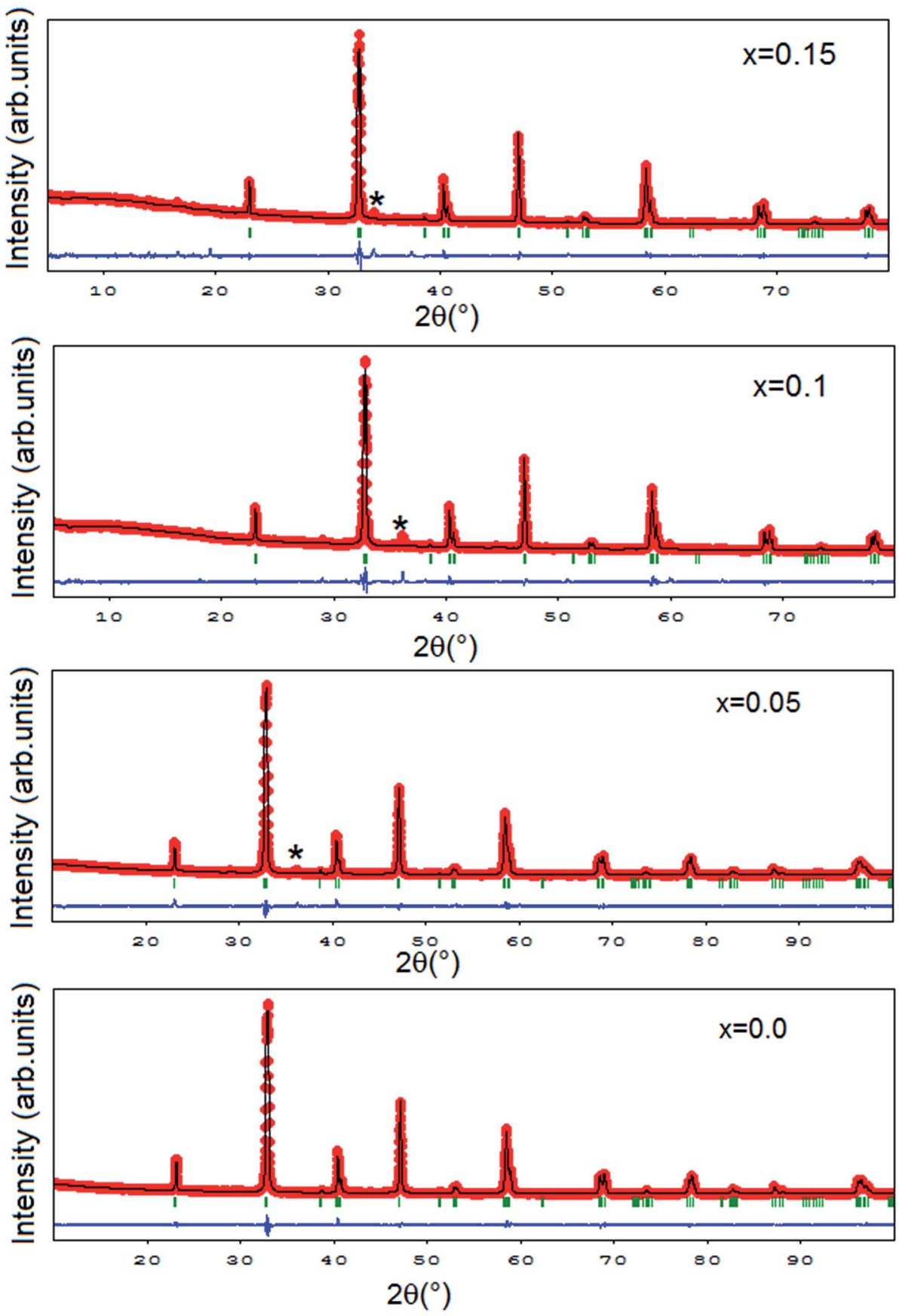

Fig. 1 XRD patterns of the XRD Rietveld refinement results for $\mathrm{La}_{0.8-x} \square_{x} \mathrm{Na}_{0.2} \mathrm{MnO}_{3}(0 \leq x \leq 0.15)$ at $\mathrm{RT}$ showing the presence of a manganite as the majority phase and a minor secondary phase. Small extra peaks of the secondary phase are marked by black asterisks. The difference between the measured (red color) and calculated data (black color) is plotted in the bottom (blue color). Green bars correspond to Bragg positions.

the paramagnetic Curie temperature $\theta_{\mathrm{p}}$ is found to be $\sim 335$, 328,326 and $323 \mathrm{~K}$ for $x=0,0.05,0.1$ and 0.15 , respectively. $\theta_{\mathrm{p}}$ decreases with $x$ content following the same trend as $T_{\mathrm{C}}$. The positive values of $\theta_{\mathrm{p}}$ reveal the existence of a ferromagnetic exchange interaction between the nearest neighbors in the paramagnetic region. Moreover, the obtained values are slightly higher than the corresponding $T_{\mathrm{C}}$. This may be due to the existence of short-range FM correlation in the PM state which is related to the presence of a magnetic inhomogeneity. ${ }^{35}$ Fitting the linear $1 / \chi(T)$ data to the Curie Weiss law introduces $C$ values for all samples. Using these values, we obtained the experimental effective paramagnetic moment $\mu_{\mathrm{eff}}^{\exp }$. It is noted that the $\mu_{\mathrm{eff}}^{\exp }$ values for $x=0,0.05,0.1$ and 0.15 are 4.44, 4.23, 5.085 and $5.107 \mu_{\mathrm{B}}$ respectively. Assuming orbital momentum to be quenched in $\mathrm{Mn}^{3+}$ and $\mathrm{Mn}^{4+}$, commonly, the theoretical effective moment for each case is determined by the equation: $\mu_{\mathrm{eff}}^{\text {theo }}=g \sqrt{S(S+1)} \mu_{\mathrm{B}}$ where $g=2$ is the gyromagnetic factor and $S$ is the spin of the cation (the $S$ values are $3 / 2$ for $\mathrm{Mn}^{4+}$ and 
2 for $\mathrm{Mn}^{3+}$ ). The moment of the $\mathrm{La}_{0.8-x} \square_{x} \mathrm{Na}_{0.2} \mathrm{MnO}_{3}$ system is expected to originate from the moments of the $\mathrm{Mn}$ ion only; thus, the calculated effective paramagnetic moment per formula unit can be written as:

$\mu_{\mathrm{eff}}^{\text {theo }}=\sqrt{(0.8-3 x)\left[\mu_{\mathrm{eff}}^{\mathrm{th}}\left(\mathrm{Mn}^{3+}\right)\right]^{2}+(0.2+3 x)\left[\mu_{\mathrm{eff}}^{\mathrm{th}}\left(\mathrm{Mn}^{4+}\right)\right]^{2}} \mu_{\mathrm{B}}$

Considering the $\mathrm{Mn}^{3+}$ and $\mathrm{Mn}^{4+}$ magnetic moments $\left(\mu_{\mathrm{eff}}^{\mathrm{th}}\left(\mathrm{Mn}^{4+}\right) \approx 3.87 \mu_{\mathrm{B}}\right.$ and $\left.\mu_{\mathrm{eff}}^{\mathrm{th}}\left(\mathrm{Mn}^{3+}\right) \approx 4.9 \mu_{\mathrm{B}}\right), \mu_{\mathrm{eff}}^{\text {theo }}$ was calculated for all compounds as $4.712,4.565,4.415$ and $4.217 \mu_{\mathrm{B}}$ for $x=0.00,0.05,0.1$ and 0.15 , respectively. These values are not consistent with the experimental results suggesting the formation of FM clusters of $\mathrm{Mn}^{3+}-\mathrm{Mn}^{4+}$ double exchange pairs in the paramagnetic region. ${ }^{36}$ The discrepancy between the experimental and theoretical values implies that some short-range FM couplings might have been developed in the PM region contributing to the additional magnetic moments.

Table 1 Refined structural parameters at room temperature, $W / W_{0}$, Curie constant $C$, the paramagnetic Weiss temperature $\Theta_{\mathrm{p}}$, and theoretical $\mu_{\text {eff }}^{\text {th }}$ and experimental $\mu_{\text {eff }}^{\text {exp }}$ as a function of the $x$ content for $\mathrm{La}_{0.8-x} \square_{x} \mathrm{Na}_{0.2} \mathrm{MnO}_{3}(\mathrm{O} \leq x \leq 0.15)$ samples

\begin{tabular}{lllll}
\hline & $x=0$ & $x=0.05$ & $x=0.1$ & $x=0.15$ \\
\hline$a(\AA)$ & $5.488(3)$ & $5.483(2)$ & $5.481(9)$ & $5.480(9)$ \\
$b(\AA)$ & $5.488(3)$ & $5.483(2)$ & $5.481(9)$ & $5.480(9)$ \\
$c(\AA)$ & $13.330(4)$ & $13.310(4)$ & $13.319(1)$ & $13.317(8)$ \\
Volume $\left(\AA^{3}\right)$ & $347740(9)$ & $347180(1)$ & $346628(1)$ & $346399(7)$ \\
$d_{\mathrm{Mn}-\mathrm{O}}(\AA)$ & 1.949 & 1.950 & 1.951 & 1.951 \\
$\theta_{\mathrm{Mn}-\mathrm{O}-\mathrm{Mn}}\left({ }^{\circ}\right)$ & 166.09 & 164.79 & 164.31 & 164.19 \\
$\chi^{2}$ & 2.85 & 2.53 & 2.80 & 3.05 \\
$W / W_{0}\left(10^{-2}\right)$ & 9.6 & 9.571 & 9.548 & 9.54 \\
$C\left(\mu_{\mathrm{B}}\right)$ & 2.465 & 2.237 & 3.233 & 3.261 \\
$\Theta_{\mathrm{p}}(\mathrm{K})$ & 335 & 328 & 326 & 323 \\
$\mu_{\text {eff }}^{\mathrm{th}}\left(\mu_{\mathrm{B}}\right)$ & 4.712 & 4.565 & 4.415 & 4.217 \\
$\mu_{\text {eff }}^{\text {exp }}\left(\mu_{\mathrm{B}}\right)$ & 4.44 & 4.23 & 5.085 & 5.107
\end{tabular}

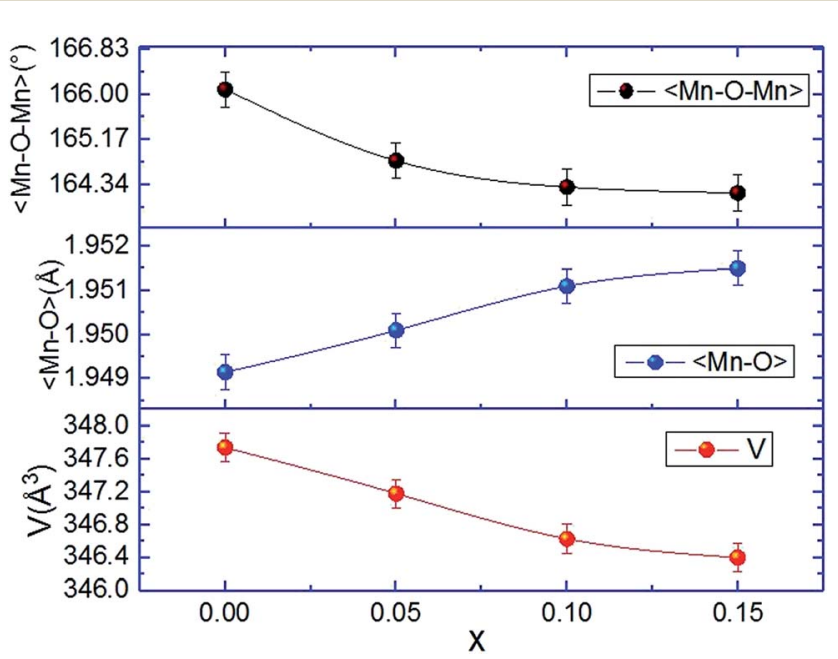

Fig. 2 Volume, $\langle\mathrm{Mn}-\mathrm{O}\rangle$ bond lengths and $\langle\mathrm{Mn}-\mathrm{O}-\mathrm{Mn}\rangle$ bond angles versus $x$ for all samples.
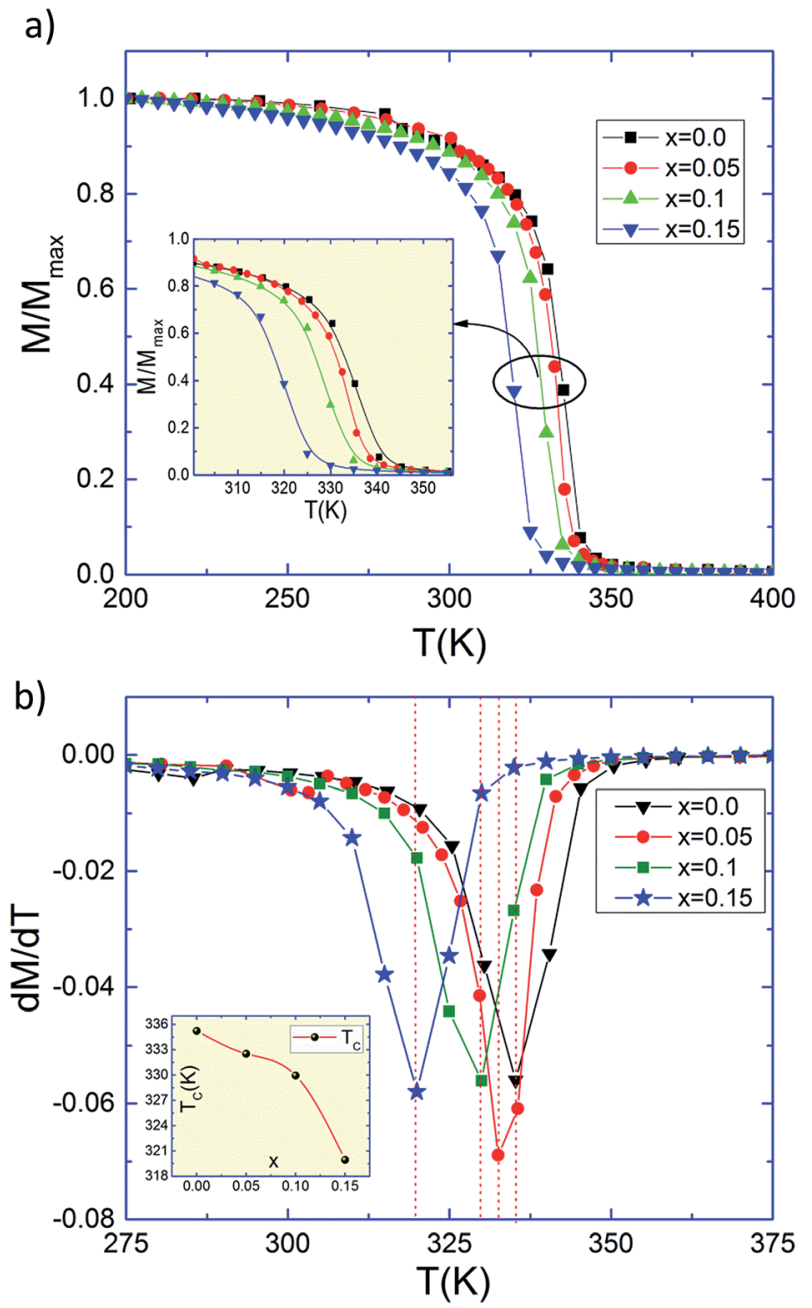

c)

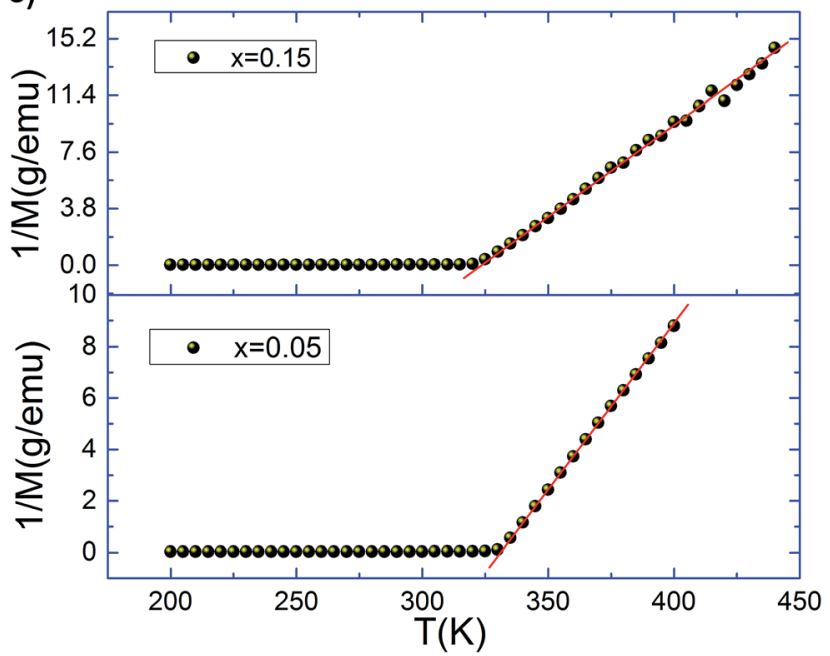

Fig. 3 (a) Magnetization measurements as a function of temperature for $\mathrm{La}_{0.8-x} \square_{x} \mathrm{Na}_{0.2} \mathrm{MnO}_{3}(0 \leq x \leq 0.15)$ samples under $0.05 \mathrm{~T}$. (b) $\mathrm{d} M /$ $\mathrm{d} T$ as a function of temperature of $\mathrm{La}_{0.8-x} \square_{x} \mathrm{Na}_{0.2} \mathrm{MnO}_{3}(0 \leq x \leq 0.15)$. The inset shows the Curie temperature evolution as a function of La content for $\mathrm{La}_{0.8-x} \square_{x} \mathrm{Na}_{0.2} \mathrm{MnO}_{3}(0 \leq x \leq 0.15)$. (c) Temperature dependence of the inverse of magnetic susceptibility for $L_{0.8-x} \square_{x}$ $\mathrm{Na}_{0.2} \mathrm{MnO}_{3}(x=0.0,0.05,0.1$ and 0.15$)$. The red line presents the linear fit at high temperature. 


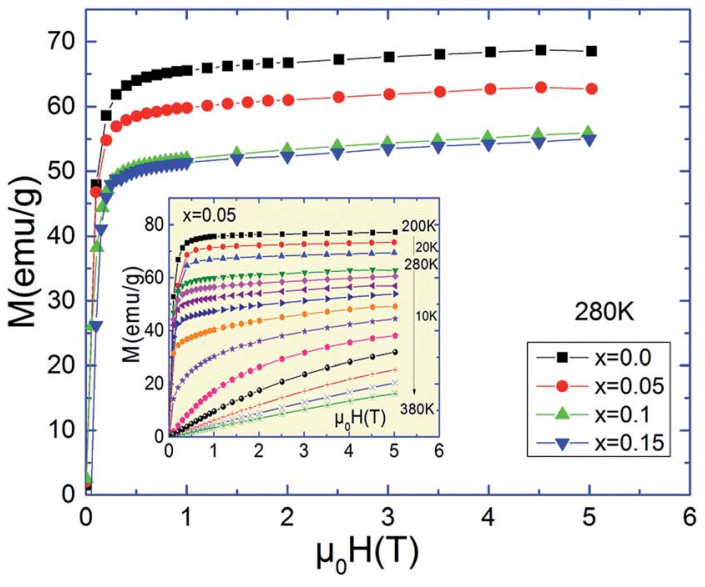

Fig. 4 Variation of the magnetization as a function of applied magnetic field at different temperatures for $\mathrm{La}_{0.8} \mathrm{Na}_{0.2-x} \square_{x} \mathrm{MnO}_{3}(\mathrm{O} \leq$ $x \leq 0.15)$ samples at $280 \mathrm{~K}$. Inset shows isothermal magnetization curves at various temperatures for $x=0.05$.

Fig. 4 presents the isothermal magnetization curves for $\mathrm{La}_{0.8-x} \square_{x} \mathrm{Na}_{0.2} \mathrm{MnO}_{3}(0 \leq x \leq 0.15)$ These $M\left(\mu_{0} H\right)$ measurements are measured near the magnetic transition with increasing magnetic field in a wide temperature range. It can be seen that $M\left(\mu_{0} H\right)$ versus magnetic applied field up to $5 \mathrm{~T}$ recorded at $280 \mathrm{~K}$ shows a typical ferromagnetic nature for $\mathrm{La}_{0.8-x} \square_{x} \mathrm{Na}_{0.2} \mathrm{MnO}_{3}$. The magnetization increases sharply with magnetic applied field for $\mu_{0} H=1 \mathrm{~T}$ and then saturates. It can be seen that magnetization decreased as the lanthanumdeficiency in the $\mathrm{La}_{0.8-x} \square_{x} \mathrm{Na}_{0.2} \mathrm{MnO}_{3}$ sample increased. This verifies that a vacancy gets incorporated into each sample proportionally to the amount of the $x$ deficiency. This should be related to the observation of the enlarged $\mathrm{Mn}-\mathrm{O}$ bond length and reduced $\mathrm{Mn}-\mathrm{O}-\mathrm{Mn}$ bond angle for our system. The inset of Fig. 4 shows isothermal magnetization curves for the $\mathrm{La}_{0.75} \square_{0.05} \mathrm{Na}_{0.2} \mathrm{MnO}_{3}$ sample, measured under an applied magnetic field ranging from $0-5 \mathrm{~T}$ and at a temperature ranging from 200-380 K. At $T<T_{\mathrm{C}}$, the $M\left(\mu_{0} H\right)$ curves are non-linear corresponding to the FM state and become linear at $T>T_{\mathrm{C}}$ corresponding to the PM state.

\subsection{Magnetocaloric properties}

According to thermodynamics, magnetic entropy change $\Delta S$ caused by the variation of applied magnetic field from 0 to $\mu_{0} H_{\max }$ is given by:

$$
\Delta S\left(T, \mu_{0} H_{\max }\right)=S\left(T, \mu_{0} H_{\max }\right)-S(T, 0)=\int_{0}^{\mu_{0} H_{\max }}\left(\frac{\partial S}{\partial H}\right)_{T} \mathrm{~d} \mu_{0} H
$$

From the magnetization measurements made at discrete field and temperature intervals $\Delta S$ can be approximately evaluated by the following expression:

$\Delta S_{\mathrm{M}}\left(T, \mu_{0} H_{\max }\right)=\sum_{i} \frac{M_{i+1}\left(T_{i+1}, \mu_{0} H_{\max }\right)-M_{i}\left(T_{i}, \mu_{0} H_{\max }\right)}{T_{i+1}-T_{i}} \Delta \mu_{0} H$ a)
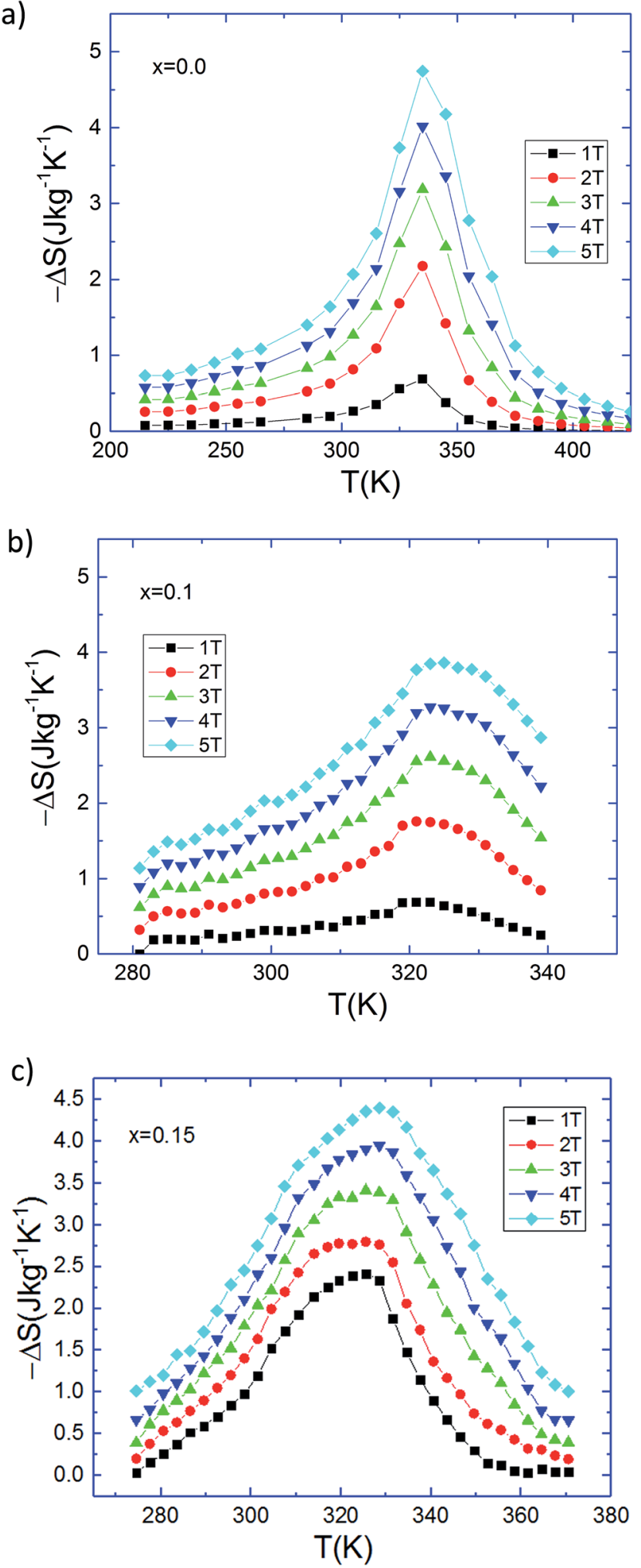

Fig. 5 Magnetic entropy change versus temperature for the $L_{0.8^{-}}$ $\mathrm{Na}_{0.2-x} \square_{x} \mathrm{MnO}_{3}$ samples under several magnetic applied field changes: (a) $x=0.00$, (b) $x=0.10$, and (c) $x=0.15$.

In this expression, $M_{i}$ and $M_{i+1}$ are the experimental values of magnetization measured, under an applied magnetic field $\mu_{0} H$, at the temperatures $T_{i}$ and $T_{i+1}$, respectively. 


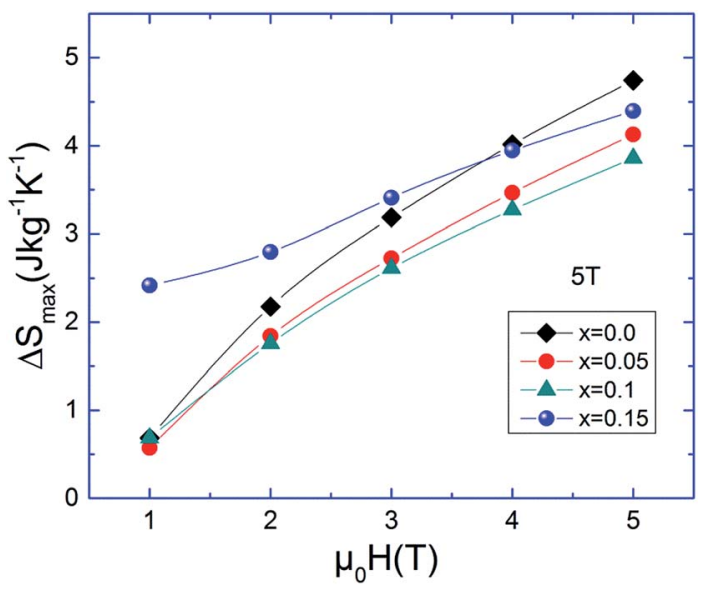

Fig. 6 The magnetic field dependence of $\Delta S_{\max }$ for $\operatorname{La}_{0.8} \mathrm{Na}_{0.2-x} \square_{x^{-}}$ $\mathrm{MnO}_{3}(0 \leq x \leq 0.15)$.

The magnetic entropy change, $-\Delta S$, induced by the magnetic field change was calculated using the $M\left(\mu_{0} H\right)$ data. In the neighborhood of room temperature, the $\mathrm{La}_{0.8-x} \square_{x} \mathrm{Na}_{0.2^{-}}$ $\mathrm{MnO}_{3}$ system is significant compared with alkaline-earth-doped lanthanide manganites such as $\mathrm{La}-\mathrm{A}(\mathrm{Ca}, \mathrm{Ba}$ and $\mathrm{Sr})-\mathrm{MnO}_{3} \cdot{ }^{37}$ Fig. 5 shows the temperature dependence of $-\Delta S$ for different applied magnetic field changes for $x=0,0.1$ and 0.15 . The obtained negative sign of the magnetic entropy change means that heat is released by the adiabatic change of the magnetic field confirming the ferromagnetic behavior of our lacunar samples. It can be seen that $\Delta S$ depends on both $T$ and $\mu_{0} H$. The magnetic entropy change increases to a maximum value $\left(\Delta S_{\max }\right)$ when the temperature approaches Curie temperature and reaches a maximum value around $T_{\mathrm{C}}$. There is, however, a notable change in the shape of the $-\Delta S(T)$ curves, specifically, increasing lanthanum-deficiency content gives an increase in the width (see Fig. 5) and alters the overall peak structure to have a relatively flat shape more typical of magnetocaloric materials with second order phase transitions. The largest changes in magnetic entropy take place near $T_{\mathrm{C}}$, which is a property of simple ferromagnets due to the efficient ordering of magnetic moments induced by the magnetic field at the ordering temperature. Basically, a broad peak on the $\Delta S(T)$ curves appears near the respective $T_{\mathrm{C}}$, unlike the sharp peak typical of $\mathrm{La}_{2 / 3} \mathrm{Ca}_{1 / 3} \mathrm{MnO}_{3},{ }^{38}$ where the phase transition is of the first order accompanied by hysteresis. ${ }^{39}$ a)

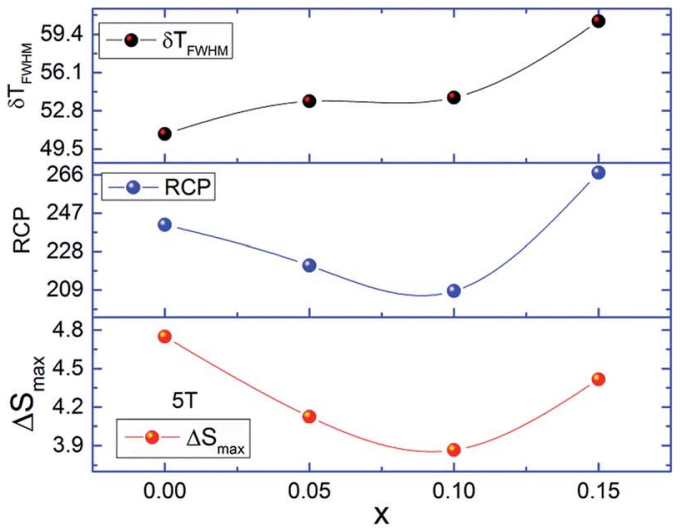

c)

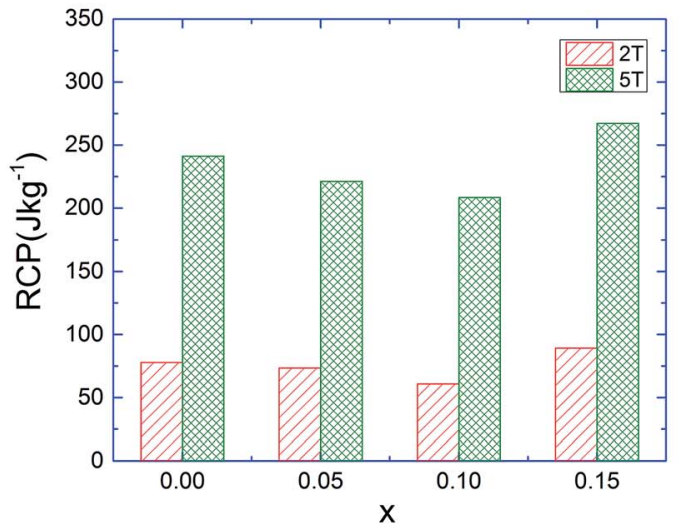

b)

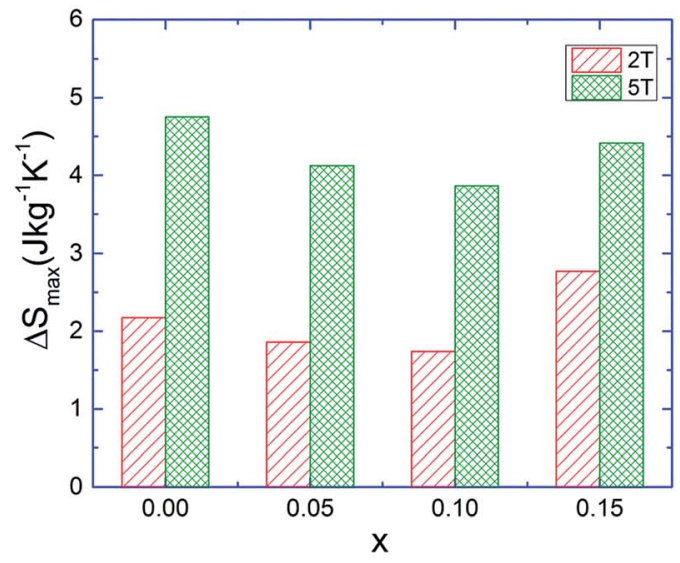

d)

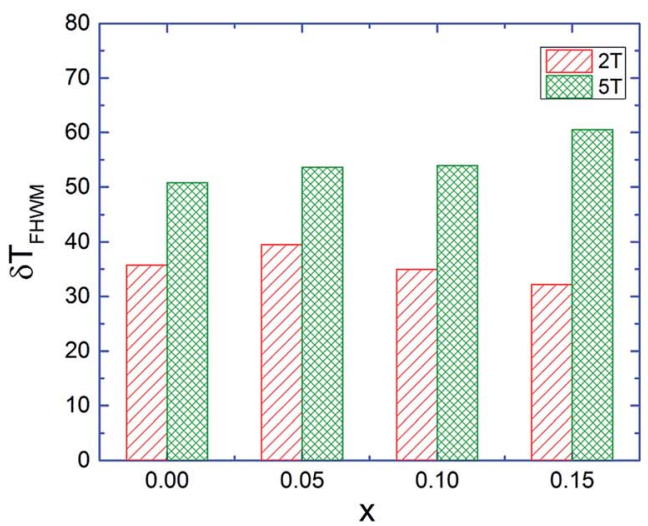

Fig. 7 Variation of $\Delta S_{\text {max }}, \delta T_{\text {FWHM }}$ and RCP with La-deficiency. (a) for $5 \mathrm{~T}$ and $(\mathrm{b}-\mathrm{d})$ for 2 and $5 \mathrm{~T}$. 
The magnitude of change in the magnetic entropy of the $\mathrm{La}_{0.8-x} \square_{x} \mathrm{Na}_{0.2} \mathrm{MnO}_{3}$ system is significant but lower than that with pure gadolinium (Gd) and ntermetallic $\mathrm{Gd}_{5} \mathrm{Si}_{2} \mathrm{Ge}_{2}$, which are considered the most conspicuous magnetocaloric materials at room temperature. Unfortunately, the $\mathrm{Gd}$ and the $\mathrm{Gd}_{5} \mathrm{Si}_{2} \mathrm{Ge}_{2}$ materials are more expensive and oxidizable in air. Compared to Gd, our manganites present some advantages including low production cost, chemical stability, high resistivity, and corrosion-free effects. It is clear from Fig. 6 that the magnitude of the peak increases with increasing value of magnetic field for each composition. The main panel of Fig. 7a shows the variations in $\Delta S$, RCP and $\Delta T_{\mathrm{FWHM}}$ under $\Delta\left(\mu_{0} H\right)=5 \mathrm{~T}$ as functions of the La-deficiency amount. While $x$ increases monotonically, $\Delta T_{\mathrm{FWHM}}$ increases; however, the relative cooling power (RCP) shows a maximum value of $\sim 268 \mathrm{~J} \mathrm{~kg}^{-1}$ for $x=0.15$ and a minimum value of $\sim 210 \mathrm{~J} \mathrm{~kg}^{-1}$ for $x=0.1$. The obtained values are comparable to about $\sim 65.3 \%$ for $x=0.15$ and $\sim 51.2 \%$ for $x=0.1$ of that of pure $\mathrm{Gd}\left(\mathrm{RCP}=410 \mathrm{~J} \mathrm{~kg}^{-1}\right.$ (ref. 40$\left.)\right)$ which is considered the most conspicuous magnetocaloric material at room temperature. Thus, this indicates that the RCP value is large revealing the applicability of $\mathrm{La}_{0.8-x} \square_{x} \mathrm{Na}_{0.2} \mathrm{MnO}_{3}$ in cooling devices and suggests that these compounds can thus be used in active magnetic refrigeration as suggested by Barclay. ${ }^{41}$

A comparison of the thermomagnetic properties in the $\mathrm{La}_{0.8-x} \square_{x} \mathrm{Na}_{0.2} \mathrm{MnO}_{3}$ series at $5 \mathrm{~T}$ and $2 \mathrm{~T}$ magnetic fields is depicted in Fig. 7b, c and d respectively. However, it is interesting to notice that RCP reaches a maximum for the $x=0.15$ lanthanum-vacancy level; for this composition, with $T_{\mathrm{C}}$ still around room temperature, the sharpness of the ferromagnetic transition makes it a potential candidate competitive with stateof-the art conventional refrigerant materials. Earlier investigations explain that the large MCE in perovskite manganites such as lacunar systems can originate from the spin-lattice coupling related to the magnetic ordering process. Because of this coupling mechanism, the lattice structural change in the $\mathrm{Mn}-\mathrm{O}$ bond distances and $\mathrm{Mn}-\mathrm{O}-\mathrm{Mn}$ bond angles with temperature which exhibit variation in volume can cause an additional change in the magnetic properties of the magnetic substance. ${ }^{42}$

For practical MCE use, it is better to have some information about the change in specific heat $\Delta C_{\mathrm{P}}$ of the compounds, which is desirable for the fulfillment of a magnetic refrigerator. In our case, the $\Delta C_{\mathrm{P}}$ associated with magnetic field changes from zero to $\mu_{0} H$ can be deduced from $\Delta S$ induced in the material, by the following expression:

$$
-\Delta C_{\mathrm{P}}=T \frac{\partial \Delta S}{\partial T}
$$

Through this relation, $\Delta C_{\mathrm{P}}$ values for several maximum applied magnetic fields ranging from 1 to $5 \mathrm{~T}$ of $\mathrm{La}_{0.8-x} \square_{x^{-}}$ $\mathrm{Na}_{0.2} \mathrm{MnO}_{3}$ with $x=0,0.1$ and 0.15 are presented in Fig. 8. One can see clear anomalies around $T_{\mathrm{C}}$ in all curves, which are due to the magnetic phase transition. ${ }^{43,44}$ The magnitude of $\Delta C_{\mathrm{P}}$ varies suddenly from (+) values to (-) values near $T_{\mathrm{C}}$ and quickly decreases with decreasing temperature. The sum of the two fractions is the magnetic contribution to the total specific heat

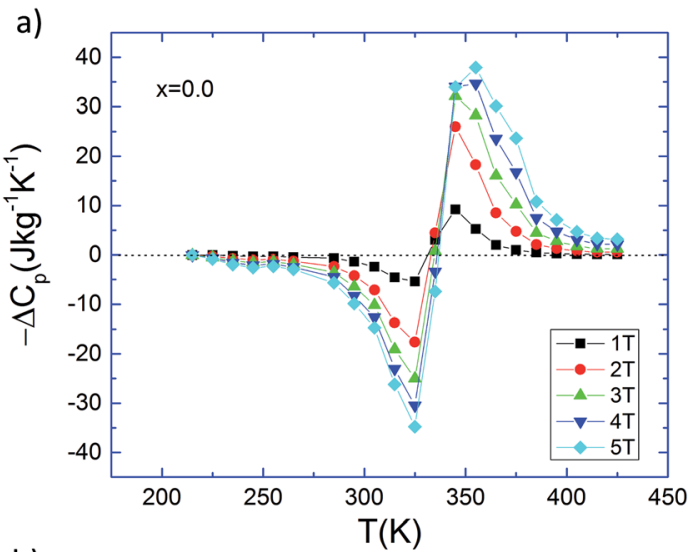

b)

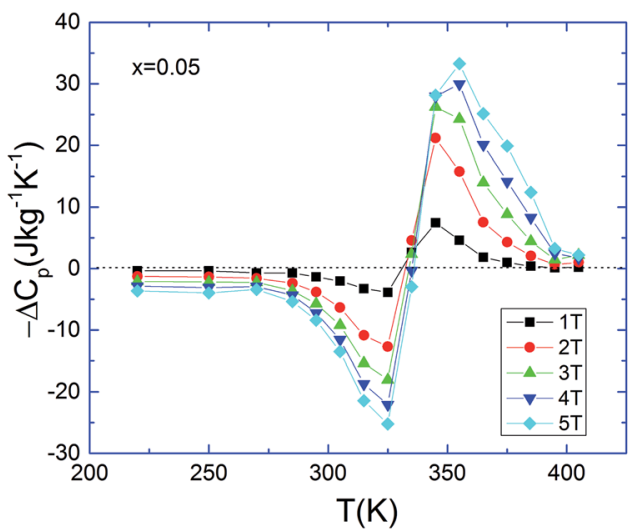

c)

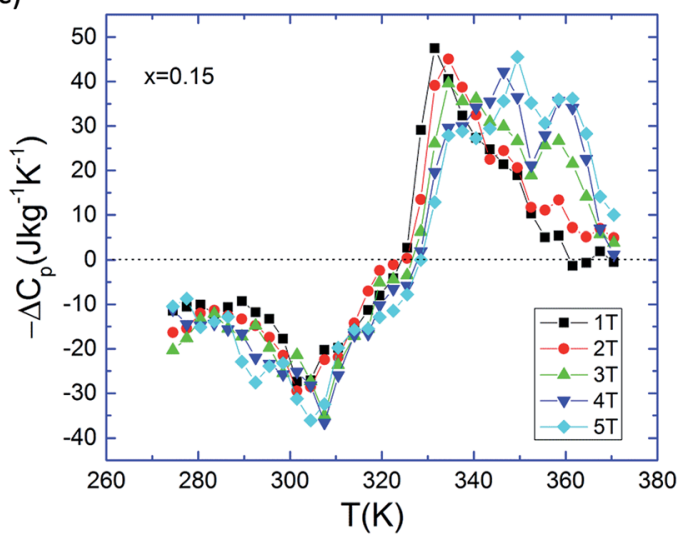

Fig. 8 The heat capacity changes $-\Delta C_{p}$ as a function of temperature for $\mathrm{La}_{0.8} \mathrm{Na}_{0.2-x} \square_{x} \mathrm{MnO}_{3}$ (a) $x=0.00$, (b) $x=0.05$, and (c) $x=0.15$ compounds.

which involves the cooling or heating power of the magnetic heat pumps and refrigerators. ${ }^{45}$ Specific heat presents the advantage of delivering values required for further pump or refrigerator design, should the sample in question be selected. ${ }^{46}$

Fig. 9 presents the temperature dependence of the exponent $n$ for $\mathrm{La}_{0.8-x} \square_{x} \mathrm{Na}_{0.2} \mathrm{MnO}_{3}(x=0$ and $x=0.15)$ describing the field dependence of the maximum magnetic entropy changes calculated locally from $n\left(T, \mu_{0} H\right)=\frac{\operatorname{d} \ln (|\Delta S|)}{\operatorname{dn}\left(\mu_{0} H\right)}$ where $n$ is related to the magnetic state of ferromagnetic materials. The value of $n$ depends on the values of the applied field and temperature. For our samples, it can be noted from the obtained curves that the 


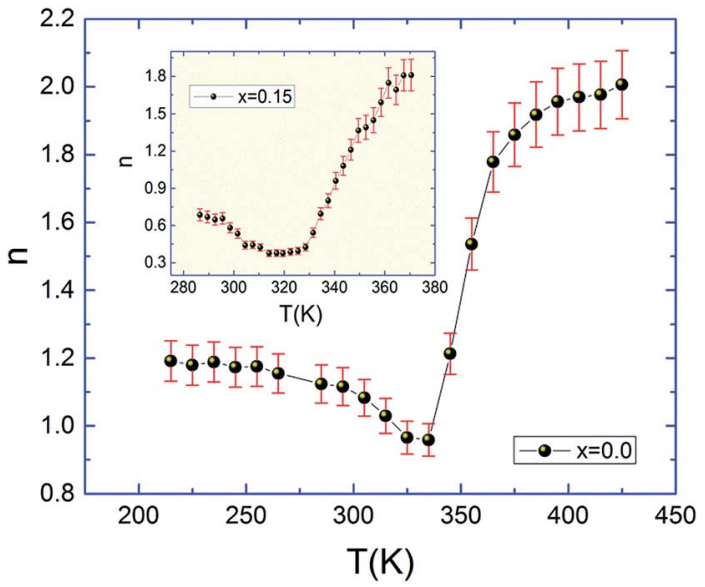

Fig. 9 Temperature dependence of exponent $n$ for $x=0.0$ and $x=$ 0.15 .

value of $n$ reaches 2 above the Curie temperature and 1 far below the Curie temperature. The $n$ exponent exhibits a moderate decrease with increasing temperature, with a minimum value in the vicinity of the transition temperature, sharply increasing above $T_{\mathrm{C}}$. This exponent takes a minimum value at $T_{\mathrm{C}}$. The obtained values of $n$ are significantly different than $2 / 3$, as predicted by the mean field theory. Thus, this variation of $n(T)$ indicates the inhomogeneous character for all samples, and among the several forms of the inhomogeneous phase is the existence of local inhomogeneities or superparamagnetic clusters in the vicinity of the Curie temperature in the $\mathrm{La}_{0.8-x} \square_{x^{-}}$ $\mathrm{Na}_{0.2} \mathrm{MnO}_{3}$ compounds. A similar behavior has been observed in other perovskite materials. ${ }^{47-49}$

According to the suggestion by Franco and Conde, ${ }^{50}$ universal scaling analysis helps to determine the nature of the magnetic phase transition (first or second order) in our samples. ${ }^{51}$ This model can be confirmed by normalizing maximum magnetic entropy changes and temperatures, as defined by the following relation: ${ }^{52}$

$$
\Delta S^{\prime}\left(T, \Delta \mu_{0} H=\mu_{0} H_{\max }\right)=\frac{\Delta S\left(T, \Delta \mu_{0} H=\mu_{0} H_{\max }\right)}{\Delta S^{\text {peak }}\left(T, \Delta \mu_{0} H=\mu_{0} H_{\max }\right)}
$$

The temperature axis was rescaled in a different way below and above $T_{\mathrm{C}}$, just by indicating that the position of the reference temperatures $T_{\mathrm{r} 1}$ and $T_{\mathrm{r} 2}$ of each curve corresponds to to $\theta= \pm 1:^{53}$

$$
\theta=\left\{\begin{array}{l}
-\left(T-T_{\mathrm{C}}\right) /\left(T_{\mathrm{r} 1}-T_{\mathrm{C}}\right) ; \quad T \leq T_{\mathrm{C}} \\
\left(T-T_{\mathrm{C}}\right) /\left(T_{\mathrm{r} 2}-T_{\mathrm{C}}\right) ; \quad T>T_{\mathrm{C}}
\end{array}\right.
$$

Here, the two additional reference points are chosen such that $\Delta S\left(T_{\mathrm{r} 1}\right)=\Delta S\left(T_{\mathrm{r} 2}\right)=\Delta S^{\text {peak }} / 2$. This method should remove the temperature and field dependence of the set of $\Delta S\left(\mu_{0} H, T\right)$ plots so that all curves processed with the same scaling protocol collapse onto a single universal curve. This procedure has been successfully applied to several families of magnetic material. ${ }^{54-58}$ Fig. 10 shows that the rescaled $\Delta S$ data for several
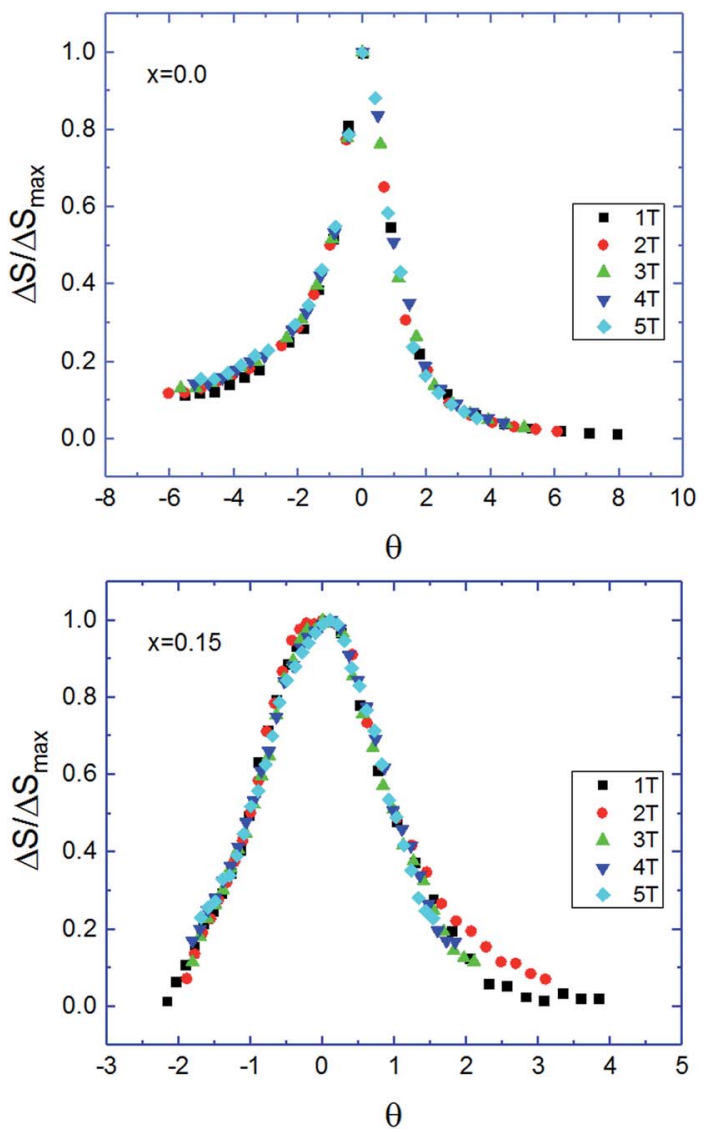

Fig. 10 Universal behavior of the scaled entropy change curves at different fields for $x=0.0$ and $x=0.15$

applied fields and temperatures can collapse onto a single curve, confirming the master curve behavior in this system and clearly indicating that the magnetic phase transition in $\mathrm{La}_{0.8-x} \square_{x} \mathrm{Na}_{0.2} \mathrm{MnO}_{3}$ is second order. Therefore, materials undergoing second-order transition are preferred for magnetic cooling applications.

\section{Conclusion}

To summarize, we have investigated the effect of lanthanum vacancy on the structural, magnetic, and magnetocaloric properties of $\mathrm{La}_{0.8-x} \square_{x} \mathrm{Na}_{0.2} \mathrm{MnO}_{3}(0 \leq x \leq 0.15)$. The rhombohedral samples are produced from cheap and abundant elements using a simple and straight forward process making them economically attractive for room temperature applications. The increase of lanthanum deficiency induces local distortions in the Mn-O-Mn bonds and consequently causes a random distribution in the magnetic exchange interactions. The competition between magnetic interactions leads to the appearance of an inhomogeneous magnetic state in our lacunar system. Our samples exhibit second order PM-FM transition with decreasing temperature and their Curie temperatures decrease. Consequently, the ability to tune the temperature transition close to room temperature is revealed to be possible by changing the lanthanum-deficiency content as well. The 
investigation of the magnetocaloric properties reveals a broad peak of $-\Delta S$ around $T_{\mathrm{C}}$. As a main result from a practical point of view, for $x=0.15$, the relative cooling power shows a maximum value of $\sim 268 \mathrm{~J} \mathrm{~kg}^{-1}$ under an applied magnetic field of $5 \mathrm{~T}$, which is sufficient for potential applications in magnetic cooling near room temperature due to the easy synthesis and processing, high chemical stability, very low cost and high chemical stability of these compounds. The $\Delta S$ data for different compositions distribute on a single master curve, further confirming the nature of second-order magnetic transition needed for practical applications.

\section{Conflicts of interest}

There are no conflicts to declare.

\section{References}

1 A. M. Tishin and Y. I. Spichkin, The Magnetocaloric Effect and its Applications, Institute of Physics Publishing, Bristol, 2003.

2 R. Szymczak, M. Czepelak, R. Kolano, A. Kolano-Burian, B. Krzymańska and H. Szymczak, Magnetocaloric effect in $\mathrm{La}_{1-x} \mathrm{Ca}_{x} \mathrm{MnO}_{3}$ for $x=0.3,0.35$, and 0.4, J. Mater. Sci., 2008, 43, 1734.

3 V. K. Pecharsky and K. A. Gschneidner Jr, Giant Magnetocaloric Effect in $\mathrm{Gd}_{5}\left(\mathrm{Si}_{2} \mathrm{Ge}_{2}\right)$, Phys. Rev. Lett., 1997, 78, 4494.

4 V. K. Pecharsky and K. A. Gschneidner Jr, $\mathrm{Gd}_{5}\left(\mathrm{Si}_{x} \mathrm{Ge}_{1-x}\right)_{4}$ : An Extremum Material, Adv. Mater., 2001, 13, 683.

5 M. H. Phan and S. C. Yu, Review of the magnetocaloric effect in manganite materials, J. Magn. Magn. Mater., 2007, 308, 325.

6 R. M'nassri, Searching the conditions for a table-like shape of the magnetic entropy in the magnetocaloric $\mathrm{LBMO}_{2.98} /$ $\mathrm{LBMO}_{2.95}$ composite, Eur. Phys. J. Plus, 2016, 131, 392.

7 R. M'nassri, W. Cheikhrouhou-Koubaa, M. Koubaa, N. Boudjada and A. Cheikhrouhou, Magnetic and magnetocaloric properties of $\operatorname{Pr}_{0.6-\mathrm{x}} \mathrm{Eu}_{\mathrm{x}} \mathrm{Sr}_{0.4} \mathrm{MnO}_{3}$ manganese oxides, Solid State Commun., 2011, 151, 1579.

8 R. M'nassri, W. Cheikhrouhou-Koubaa, M. Kouba and A. Cheikhrouhou, Effect of strontium substitution on the physical properties of $\mathrm{Nd}_{0.5} \mathrm{Ca}_{0.5-\mathrm{x}} \mathrm{Sr}_{\mathrm{x}} \mathrm{MnO}_{3}(0.0 \leq \mathrm{x} \leq 0.5)$ manganites, IOP Conf. Ser.: Mater. Sci. Eng., 2012, 28, 012050.

9 R. M'nassri, W. Cheikhrouhou-Koubaa, N. Boudjada and A. Cheikhrouhou, Magnetocaloric Effects in $\mathrm{Pr}_{0.6-\mathrm{x}} \mathrm{Er}_{\mathrm{x}} \mathrm{Sr}_{0.4} \mathrm{MnO}_{3} \quad(0.0 \leq \mathrm{x} \leq 0.2) \quad$ Manganese Oxides, $J$. Supercond. Novel Magn., 2013, 26, 1429.

10 R. M'nassri and A. Cheikhrouhou, Magnetocaloric Effect in Different Impurity Doped $\mathrm{La}_{0.67} \mathrm{Ca}_{0.33} \mathrm{MnO}_{3}$ Composite, $J$. Supercond. Novel Magn., 2014, 27, 421.

11 P. Lampen, A. Puri, M.-H. Phan and H. Srikanth, Structure, magnetic, and magnetocaloric properties of amorphous and crystalline $\mathrm{La}_{0.4} \mathrm{Ca}_{0.6} \mathrm{MnO}_{3+\delta}$ nanoparticles, J. Alloys Compd., 2012, 512, 94.

12 R. M'nassri and A. Cheikhrouhou, Evolution of Magnetocaloric Behavior in Oxygen Deficient $\mathrm{La}_{2 / 3} \mathrm{Ba}_{1 /}$ ${ }_{3} \mathrm{MnO}_{3-\delta}$ Manganites, J. Supercond. Novel Magn., 2014, 27, 1463.
13 A. J. Millis, P. B. Littlewood and B. I. Shraiman, Double Exchange Alone Does Not Explain the Resistivity of $\mathrm{La}_{1-\mathrm{x}} \mathrm{Sr}_{\mathrm{x}} \mathrm{MnO}$, Phys. Rev. Lett., 1995, 74, 5144.

14 L. Jian-Min, C. H. A. Huan, Y.-W. Du, D. Feng and Z. X. Shen, Magnetic-field-tunable charge carrier localization in sintered polycrystalline $\mathrm{La}_{0.75} \mathrm{Ca}_{0.25} \mathrm{MnO}$, Phys. Rev. B: Condens. Matter Mater. Phys., 2000, 63, 024416.

15 P. Alvarez-Alonso, J. L. Sánchez Llamazares, C. F. SánchezValdés, G. J. Cuello, V. Franco, P. Gorria and J. A. Blanco, On the broadening of the magnetic entropy change due to Curie temperature distribution, J. Appl. Phys., 2014, 115, 17A929.

16 V. K. Pecharsky, K. A. Gschneidner and A. O. Tsokol, Recent developments in magnetocaloric materials, Rep. Prog. Phys., 2005, 68, 1479.

17 B. G. Shen, J. R. Sun, F. X. Hu, et al., Recent progress in exploring magnetocaloric materials, Adv. Mater., 2009, 21, 4545-4564.

18 E. Brück, O. Tegus, D. T. Cam Thanh, et al., A review on Mn based materials for magnetic refrigeration: structure and properties, Int. J. Refrig., 2008, 31, 763-770.

19 C. R. H. Bahl, D. Velazquez, K. K. Nielsen, K. Engelbrecht, K. B. Andersen, R. Bulatova and N. Pryds, High performance magnetocaloric perovskites for magnetic refrigeration, Appl. Phys. Lett., 2012, 100, 121905.

20 R. M'nassri, N. C. Boudjada and A. Cheikhrouhou, Nearly constant magnetic entropy change involving the enhancement of refrigerant capacity in $\left(\mathrm{La}_{0.6} \mathrm{Ba}_{0.2} \mathrm{Sr}_{0.2} \mathrm{MnO}_{3}\right)_{1-\mathrm{x}} /\left(\mathrm{Co}_{2} \mathrm{O}_{3}\right)_{\mathrm{x}}$ composite, Ceram. Int., 2016, 42(6), 7447.

21 H. Mbarek, R. M'nasri, W. Cheikhrouhou-Koubaa and A. Cheikhrouhou, Magnetocaloric effect near room temperature in $(1-\mathrm{y}) \mathrm{La}_{0.8} \mathrm{Ca}_{0.05} \mathrm{~K}_{0.15} \mathrm{MnO}_{3} / \mathrm{y} \mathrm{La}_{0.8} \mathrm{~K}_{0.2} \mathrm{MnO}_{3}$ composites, Status Solidi A, 2014, 211, 975.

22 S. Choura Maatar, R. M'nassri, W. Cheikhrouhou-Koubaa, M. Koubaa and A. Cheikhrouhou, Structural, magnetic and magnetocaloric properties of $\mathrm{La}_{0.8} \mathrm{Ca}_{0.2-\mathrm{x}} \mathrm{Na}_{\mathrm{x}} \mathrm{MnO} 3$ manganites $(0 \leq \mathrm{x} \leq 0.2)$, J. Solid State Chem., 2015, 225, 83.

23 W. Boujelben, A. Cheikhrouhou, J. Pierre and J. C. Joubert, Ferromagnetism in the lacunar (Pr, $\mathrm{Sr}) \mathrm{MnO}_{3}$ perovskite manganites, Phys. B, 2002, 321, 37.

24 S. Choura-Maatar, R. M'nassri, W. Cheikhrouhou-Koubaa, M. Koubaa, A. Cheikhrouhou and E. K. Hlil, Sodium deficiency effects on the structural, magnetic and magnetocaloric properties of $\mathrm{La}_{0.8} \mathrm{Na}_{0.2-\mathrm{x}} \square{ }_{\mathrm{x}} \mathrm{MnO}_{3}(0 \leq \mathrm{x} \leq$ 0.15), J. Magn. Magn. Mater., 2017, 433, 239.

25 M. Ellouze, W. Boujelben, A. Cheikhrouhou, H. Fuess and R. Madar, Solid State Commun., 2002, 124, 125.

$26 \mathrm{~W}$. Boujelben, A. Cheikhrouhou and J. C. Joubert, Ferromagnetism in lacunar perovskite manganites $\mathrm{Pr}_{0.7} \mathrm{Sr}_{0.3-\mathrm{x}} \mathrm{xMnO}_{3}$ and $\mathrm{Pr}_{0.7-\mathrm{x} \times \mathrm{x}} \mathrm{Sr0.3} \mathrm{MnO}_{3}$, Eur. Phys. J. B, 2001, 24, 419.

27 R. M'nassri, W. Cheikhrouhou-Koubaa, N. ChnibaBoudjada and A. Cheikhrouhou, Effect of barium-deficiency on the structural, magnetic, and magnetocaloric properties of $\mathrm{La}_{0.6} \mathrm{Sr}_{0.2} \mathrm{Ba}_{0.2-\mathrm{x}} \square_{\mathrm{x}} \mathrm{MnO}_{3}(0 \leq \mathrm{x} \leq 0.15)$, J. Appl. Phys., 2013, 113, 073905. 
28 H. M. Rietveld, A Profile Refinement Method for Nuclear and Magnetic Structures, J. Appl. Crystallogr., 1965, 2, 65.

29 T. Roisnel and J. Rodriguez-Carvajal, Computer Program FULLPROF, LLB-LCSIM, May 2003.

30 R. A. Young, The Rietveld Method, Oxford University Press, New York, 1993.

31 B. Vertruyen, J.-F. Fagnard, P. Vanderbemden, M. Ausloos, A. Rulmont and R. Cloots, Electrical transport and magnetic properties of $\mathrm{Mn}_{3} \mathrm{O}_{4}-\mathrm{La}_{0.7} \mathrm{Ca}_{0.3} \mathrm{MnO}_{3}$ ceramic composites prepared by a one-step spray-drying technique, J. Eur. Ceram. Soc., 2007, 27, 3923.

32 R. D. Shanon, Structure Reports, Acta Crystallogr., Sect. A: Cryst. Phys., Diffr., Theor. Gen. Crystallogr., 1976, 32, 751.

$33 \mathrm{~W}$. Boujelben, A. Cheikh-Rouhou and J. C. Joubert, Praseodymium Deficiency Effects on the Physical Properties $\operatorname{Pr}_{0.7-\mathrm{x}} \square_{\mathrm{x}} \mathrm{Sr}_{0.3} \mathrm{MnO}_{3}$ Perovskite Manganites, $J$. Solid State Chem., 2001, 156, 68.

34 A. H. Morrish, The Physical Principles of Magnetism, IEEE Press, New York, 2001.

35 R. M'nassri, N. Chniba Boudjada and A. Cheikhrouhou, Impact of sintering temperature on the magnetic and magnetocaloric properties in $\mathrm{Pr}_{0.5} \mathrm{Eu}_{0.1} \mathrm{Sr}_{0.4} \mathrm{MnO}_{3}$ manganites, J. Alloys Compd., 2015, 626, 20.

36 R. P. Borges, F. Ott, R. M. Thomas, V. Skumryev, J. M. D. Coey, J. I. Arnaudas and L. Ranno, Field-induced transition in the paramagnetic state of $\left(\mathrm{Sm}_{0.65} \mathrm{Sr}_{0.35}\right) \mathrm{MnO}_{3}$ associated with magnetic clusters, Phys. Rev. B: Condens. Matter Mater. Phys., 1999, 60, 12847.

37 D. T. Morelli, A. M. Mance, J. V. Mantese and A. L. Micheli, Magnetocaloric properties of doped lanthanum manganite films, J. Appl. Phys., 1996, 79, 373.

38 J. Mira, J. Rivas, L. E. Hueso, F. Rivadulla and M. A. Lopez Quintela, Drop of magnetocaloric effect related to the change from first- to second-order magnetic phase transition in $\mathrm{La}_{2 / 3}\left(\mathrm{Ca}_{1-\mathrm{x}} \mathrm{Sr}_{\mathrm{x}}\right)_{1 / 3} \mathrm{MnO}_{3}$, J. Appl. Phys., 2002, 91, 8903.

39 V. S. Amaral, J. P. Araújo, Y. G. Pogorelov, J. M. B. Lopes dos Santos, P. B. Tavares, A. A. C. S. Lourenço, J. B. Sousa and J. M. Vieira, Anomalous magnetic behavior in LaCaMnO near the critical point: stable clusters and crossover to uniform ferromagnetism, J. Magn. Magn. Mater., 2001, 226, 837.

40 V. K. Pecharsky, K. A. Gschneidner and A. O. Tsokol, Rep. Prog. Phys., 2005, 68, 1479.

41 J. A. Barclay, J. Alloys Compd., 1994, 207-208, 355.

42 Z. B. Guo, Y. W. Du, J. S. Zhu, H. Huang, W. P. Ding and D. Feng, Large Magnetic Entropy Change in PerovskiteType Manganese Oxides, Phys. Rev. Lett., 1997, 78, 1142.

43 H. Yang, Y. H. Zhu, T. Xian and J. L. Jiang, Synthesis and magnetocaloric properties of $\mathrm{La}_{0.7} \mathrm{Ca}_{0.3} \mathrm{MnO}_{3}$ nanoparticles with different sizes, J. Alloys Compd., 2013, 555, 150.

44 K. Raju, N. Pavan Kumar, P. Venugopal Reddy and D. H. Yoon, Influence of $\mathrm{Eu}$ doping on magnetocaloric behavior of $\mathrm{La}_{0.67} \mathrm{Sr}_{0.33} \mathrm{MnO}_{3}$, Phys. Lett.A, 2015, 379, 1178.
45 X. X. Zhang, G. H. Wen, F. W. Wang, W. H. Wang, C. H. Yu and G. H. Wu, Magnetic entropy change in Fe-based compound $\mathrm{LaFe}_{10.6} \mathrm{Si}_{2.4}$, Appl. Phys. Lett., 2000, 77, 3072.

46 N. Kumar Swamy, N. Pavan Kumar, P. V. Reddy, M. Gupta, S. S. Samatham, D. Venkateshwarulu, et al., Specific heat and magnetocaloric effect studies in multiferroic $\mathrm{YMnO}_{3}$, J. Therm. Anal. Calorim., 2014, 119, 1191.

47 T.-L. Phan, P. Zhang, T. D. Thanh and S. C. Yu, Crossover from first-order to second-order phase transitions and magnetocaloric effect in $\mathrm{La}_{0.7} \mathrm{Ca}_{0.3} \mathrm{Mn}_{0.91} \mathrm{Ni}_{0.09} \mathrm{O}_{3}, J$. Appl. Phys., 2014, 115, 17.

48 A. Selmi, R. M'nassri, W. Cheikhrouhou-Koubaa, N. Chniba Boudjada and A. Cheikhrouhou, Effects of partial Mnsubstitution on magnetic and magnetocaloric properties in $\mathrm{Pr}_{0.7} \mathrm{Ca}_{0.3} \mathrm{Mn}_{0.95} \mathrm{X}_{0.05} \mathrm{O}_{3}$ ( $\mathrm{Cr}, \mathrm{Ni}$, Co and $\mathrm{Fe}$ ) manganites, $J$. Alloys Compd., 2015, 619, 627.

49 F. Saadaoui, R. M'nassri, H. Omrani, M. Koubaa, N. C. Boudjada and A. Cheikhrouhou, Critical behavior and magnetocaloric study in La0.6Sr0.4CoO3 cobaltite prepared by a sol-gel process, $R S C A d v ., 2016,6(56), 50968$.

$50 \mathrm{~V}$. Franco and A. Conde, Scaling laws for the magnetocaloric effect in second order phase transitions: From physics to applications for the characterization of materials, Int. J. Refrig., 2010, 33, 465473.

51 C. M. Bonilla, J. Herrero-Albillos, F. Bartolome, L. M. Garcia, M. Parra-Borderias and V. Franco, Universal behavior for magnetic entropy change in magnetocaloric materials: An analysis on the nature of phase transitions, Phys. Rev. B: Condens. Matter Mater. Phys., 2010, 81, 224424.

52 V. Franco, C. F. Conde, J. S. Blázquez, A. Conde, P. Švec, D. Janičkovič and L. F. Kiss, J. Appl. Phys., 2007, 101, 093903.

53 V. Franco, A. Conde, V. Provenzano and R. D. Shull, Scaling analysis of the magnetocaloric effect in $\mathrm{Gd}_{5} \mathrm{Si}_{2} \mathrm{Ge}_{1.9} \mathrm{X}_{0.1}(\mathrm{X}=$ Al, Cu, Ga, Mn, Fe, Co), J. Magn. Magn. Mater., 2010, 322, 218.

54 C. M. Bonilla, J. Herrero-Albillos, F. Bartolome, L. M. Garcia, M. Parra-Borderias and V. Franco, Universal behavior for magnetic entropy change in magnetocaloric materials: An analysis on the nature of phase transitions, Phys. Rev. B: Condens. Matter Mater. Phys., 2010, 81, 224424.

55 R. M'nassri and A. Cheikhrouhou, Magnetocaloric properties in ordered double-perovskite $\mathrm{Ba}_{2} \mathrm{Fe}_{1-\mathrm{x}} \mathrm{Cr}_{\mathrm{x}} \mathrm{MoO}_{6}$ $(0 \leq \mathrm{x} \leq 1)$, J. Korean Phys. Soc., 2014, 64, 879.

56 A. Sakka, R. M'nassri, N. ChnibaBoudjada, M. Ommezzine and A. Cheikhrouhou, Effect of trivalent rare earth doping on magnetic and magnetocaloric properties of $\operatorname{Pr}_{0.5}(\mathrm{Ce}, \mathrm{Eu}, \mathrm{Y})_{0.1} \mathrm{Sr}_{0.4} \mathrm{MnO}_{3}$ manganites, Appl. Phys. A: Mater. Sci. Process., 2016, 122, 1.

57 R. M'nassri, A. Selmi, N. C. Boudjada and A. Cheikhrouhou, Field dependence of magnetocaloric properties of $20 \% \mathrm{Cr}-$ doped Pr0.7Ca0.3MnO3 perovskite, J. Therm. Anal. Calorim., 2017, 129, 53-64.

58 R. M'nassri, M. Khelifi, H. Rahmouni, A. Selmi, K. Khirounic, N. Chniba-Boudjada and A. Cheikhrouhou, Study of physical properties of cobalt substituted $\mathrm{Pr}_{0.7} \mathrm{Ca} 0.3 \mathrm{MnO} 3$ ceramics, Ceram. Int., 2016, 42, 6145. 